\title{
Light and anoxia fading of Prussian blue dyed textiles
}

\author{
Claire Gervais ${ }^{1 *}$, Marie-Angélique Languille ${ }^{2,3}$, Solenn Reguer ${ }^{4}$, Chantal Garnier ${ }^{3}$ and Martine Gillet ${ }^{3}$
}

\begin{abstract}
Although Prussian blue is a popular pigment, its stability has been questioned since its discovery in 1704. Its stability upon exposure to light and anoxia remains difficult to apprehend. The present paper focuses on the relative influences of light, anoxia and type of substrate on the discoloration of Prussian blue dyed textiles. Spectrophotometry and X-ray absorption spectroscopy measurements of samples artificially aged by light in air or anoxia show that both the extent of the reduction process at the origin of Prussian blue discoloration and the aging of the textile substrate are linked and strongly differ with the environment. The complex inter-relationship existing between Prussian blue discoloration and textile degradation and the final impact it may have on the conservation of the entire system is discussed.
\end{abstract}

Keywords: Prussian blue; Textile; Fading; Anoxia; Redox chemistry; X-ray absorption spectroscopy; Spectrophotometry

\section{Background}

The pigment Prussian blue (PB) was synthesized accidentally in 1704 by the colormaker Diesbach [1]. Because of its high tinting strength and availability (it could be easily synthesized by the artists), the pigment soon became popular: It was used as early as 1710 by painters and was later employed in the first photographic printing processes as a dye, and for a wide range of manufactured objects (e.g. textiles, blueprints, stamps, etc.). Since its first use, the permanence of Prussian blue has been questioned, especially when mixed with other paints in oil paintings or when submitted to light and low-oxygen treatments [2-4]. In her reference work on the history of artist's pigments [1], Berrie describes Prussian blue as "both permanent and impermanent". Indeed, those fading processes depend a lot on the object investigated $[2,5,6]$. Moreover, the faded pigment might partially recolor when stored in the dark under oxygen $[7,8]$, puzzling conservators concerned with the preservation of Prussian blue objects and preventing them from choosing adequate conservation solutions. Can artifacts containing Prussian blue be exposed to light or preserved in an anoxic frame? Are fading-recoloration cycles safe for the objects? Are cleaning treatments for PB artifacts suitable or do they enhance the light-sensitivity of

\footnotetext{
${ }^{*}$ Correspondence: claire.gervais@bfh.ch

${ }^{1}$ Bern University of the Arts, Fellerstrasse 11, 3027 Bern, Switzerland

Full list of author information is available at the end of the article
}

Prussian blue? Can we predict the permanence of Prussian blue in objects and based on which criteria? All these practical questions require a deep understanding of the physico-chemical process(es) responsible for PB fading.

The color of Prussian blue (iron(III) hexacyanoferrate(II)) is due to intervalence charge transfer between $\mathrm{Fe}(\mathrm{II})$ and $\mathrm{Fe}(\mathrm{III})$ [9]. Upon strong light exposure, $\mathrm{Fe}(\mathrm{III})$ ions are reduced to $\mathrm{Fe}(\mathrm{II})$, the charge transfer does not take place and the reduced compound is colorless. Prussian blue fading as observed in cultural heritage objects is usually linked to this redox process, as demonstrated by recent studies dedicated to the photochemistry of Prussian blue. For instance, studies based on X-ray absorption spectroscopy at the Fe K-edge coupled with spectrophotometry investigated the reduction kinetics of Prussian blue in different environments [10], estimated the role(s) of the substrate [6] and evaluated the impact of impurities or other pigments on fading [11]. A list of intrinsic and environmental factors susceptible to influence Prussian blue fading could be underlined [6]. Nevertheless, considering the complexity of the pigment itself and its variety of use, much remains to be done to fully understand and mitigate the degradation of Prussian blue.

Beside the influence of light, the action of hypoxia/ anoxia on Prussian blue is also of interest for works of art, because anoxic frames are often used to prevent the degradation of paper-based works [12]. The literature

\section{Chemistry Central}

(c) 2014 Gervais et al.; licensee Springer. This is an Open Access article distributed under the terms of the Creative Commons Attribution License (http://creativecommons.org/licenses/by/4.0), which permits unrestricted use, distribution, and reproduction in any medium, provided the original work is properly credited. 
devoted to anoxic fading of Prussian blue is significant $[3-5,7,10,13]$, and highlighted the sensitivity of the pigment, especially in paper artworks and dyed textiles. For Prussian blue dyed textiles, anoxia was found to significantly enhance the fading, and recommendations were made to avoid long-term storage in low-oxygen environments [3,7]. These results confirmed early observations of Prussian blue's anoxic behavior for textiles by Chevreul in the nineteenth century [14]. While very informative, those studies focused principally on general color changes and the Prussian blue photochemistry within this type of sample has never been investigated so far.

This study deals with the physico-chemical investigation of Prussian blue dyed textiles and the role of light, anoxia ${ }^{\mathrm{a}}$ and type of textile on Prussian blue fading. For that purpose, we prepared modern Prussian blue dyed textiles on cotton, linen and silk. The samples underwent aging treatments that consisted in exposure to air, anoxia, air+light and anoxia+light. Fading of the samples was analyzed by spectrophotometry in addition to color difference $\Delta E^{*}$ values, and X-ray absorption spectroscopy at the Fe $\mathrm{K}$ edge was performed to investigate structural changes of Prussian blue associated with the fading. The aging treatments were also performed on undyed textiles to analyze separately the contribution of textile aging on the final discoloration of the Prussian blue textile samples. Undyed and Prussian blue dyed textiles were again analyzed by spectrophotometry after 3 years storage in dark and air, to assess their ability to recover their initial color.

\section{Methods}

\section{Sample preparation}

After washing with Marseille soap, cotton, linen and silk textiles were dyed according to a modern version [3] of Napier's recipe [15]. The tissues were soaked for 30 minutes in a solution of iron nitrate $\left(\mathrm{Fe}^{\mathrm{III}}\left(\mathrm{NO}_{3}\right)_{3} \cdot 9 \mathrm{H}_{2} \mathrm{O}\right.$, $7.65 \mathrm{~g}$ in $1 \mathrm{~L}$ water). After wringing, they were immersed in a solution of $7.56 \mathrm{~g}$ potassium hexacyanoferrate $\left(\mathrm{K}_{4} \mathrm{Fe}^{\mathrm{II}} \mathrm{CN}_{6}\right)$ and $1.9 \mathrm{~mL}$ of sulfuric acid $\left(\mathrm{H}_{2} \mathrm{SO}_{4}, 0.4 \mathrm{M}\right)$ in $1 \mathrm{~L}$ of water. This two-step immersion procedure was then repeated before soaking the clothes 2 or 3 minutes in a solution of aluminum sulphate $(0.95 \mathrm{~g}$ in $1 \mathrm{~L}$ of water $)$ in order to fix the dying. Finally, clothes were rinsed in water and dried at room temperature.

\section{Fading}

To simulate air and anoxia environments, the samples were placed in transparent bags (made of barrier film $\mathrm{OPP} / \mathrm{EVOH} / \mathrm{PE}$ ) filled with air or nitrogen humidified to $50 \%$ relative humidity, respectively. The anoxia bags contained oxygen scavengers, which guaranteed a concentration in oxygen less than $0.1 \%$. Once filled, the bags were thermo-sealed and placed into a light weathering chamber equipped with a metal halide lamp (2500 W Hydrargyrum
Medium-arc Iodide (HMI) lamp) and a window glass filter that removed UV radiations below $325 \mathrm{~nm}$. Light aging was performed at $\mathrm{T}=25^{\circ} \mathrm{C}$ and $50 \% \mathrm{RH}$. We attempted to mimick alteration during 3400 museum hours (based on a 50 lux exposure) by a fading treatment of about 170 Klux at the surface of the samples and an irradiance of about $1200 \mathrm{~W} / \mathrm{m}^{2}$. Two series of samples including undyed samples of cotton and linen were prepared and underwent the fading treatment (i.e air, anoxia, air+light, anoxia+light) for five days. Results of the first series is presented in the paper, while those of the second series are shown in Additional file 1. Undyed silk samples were not included in sample set due to issues with the fading treatment. For each sample, a part was hidden from the light as a reference. Color was measured before treatment (Reference) and immediately after light exposure: samples were analyzed within minutes after their removal from the transparent bags. They were brought within the day onto the DiffAbs beamline to be analyzed by X-ray absorption spectroscopy. Following a 3-year period of dark-storage (in air, $50 \% \mathrm{RH}$ ), the color of samples faded in air were reassessed.

\section{Spectrophotometry}

Color measurements of the samples were performed with a sphere spectrophotometer X-Rite SP64, which provides reflectance spectra (resolution $10 \mathrm{~nm}$ ) and $\mathrm{L}^{*} \mathrm{a}^{*} \mathrm{~b}^{*}$ color parameters of the sample with $L^{*}$ indicating light-dark, $a^{*}$ indicating red-green and $b *$ indicating yellow-blue. Specular reflectance was included in the measurements. The measured area was $4 \mathrm{~mm}$ in diameter. The total color difference $\Delta E^{*}$ was calculated using the CIE $1976 \mathrm{~L}^{*}$ $a^{*} b^{*}$ equation for $10^{\circ}$ standard observer and standard illuminant D65 [9].

\section{X-ray absorption spectroscopy}

X-ray absorption near-edge structure (XANES) spectra were collected at the DiffAbs beamline of synchrotron SOLEIL. The energy scans were measured from $7.05 \mathrm{keV}$ to $7.30 \mathrm{keV}$ with $0.5 \mathrm{eV}$ energy step, using the $\mathrm{Si}(111)$ double crystal monochromator (energy resolution of $0.7 \mathrm{eV}$ ) and a macro beam spot size about $(300 \times 300) \mu \mathrm{m}^{2}$. The spectra were collected in fluorescence mode using a silicon drift detector. Calibration of the XANES spectra was performed with reference to the derivative peak of a Fe foil at $7112 \mathrm{eV}$. XANES spectra were processed with the Athena software (Iffefit 1.2.9 program suite) [16]. The preedge range background was removed by substracting a Victoreen function and the absorption background was removed using a cubic spline with a normalization range between 70 and $270 \mathrm{eV}$ after the edge. All XANES spectra presented here are the average of two normalized spectra acquired successively at the same location. For clarity, XANES derivatives were smoothed by a Savitzky-Golay 
algorithm with window size 9 and order 5 . No beam damage could be detected on sample (i.e. no change between two successive spectra and no visible alteration of the sample).

\section{Results and discussion \\ Fading of PB dyed textiles in air}

The reflectance spectra of $\mathrm{PB}$ dyed textiles before and after fading treatment in Air and Air+Light are displayed Figure 1. The strong absorption in the red region is due to the intervalence charge transfer between the two iron sites of PB taking place at $\approx 680 \mathrm{~nm}$ [17]. The global color change varies with the type of textile. PB-Linen is stable whatever the conditions; PB-Cotton is especially sensitive to light (calculated color difference between samples faded in Air and Air+Light, $\Delta E^{*}=10$ ); PB-Silk readily undergoes fading in air, a fading further enhanced by light $\left(\Delta E^{*}=12.0\right)$.

We further focused on PB-Cotton and PB-Linen samples, because they are stable in air but show a different fading behavior when exposed to light. This allows the origin of light fading to be investigated independently from natural aging of the samples in air. The global color change observed in the PB dyed textiles can have two origins, the discoloration of Prussian blue and the aging of the textile. We investigated the first one by X-ray absorption spectroscopy at the Fe K-edge and the second by reflectance spectra of undyed cotton and linen textiles faded in the same Air and Air+Light conditions.

\section{Prussian blue discoloration in faded PB dyed textiles}

XANES spectra of PB-Cotton and PB-Linen samples aged in Air and Air+Light are shown Figure 2. The shape of the spectrum is typical of Prussian blue [6]. After the edge (7120-7122 eV), it exhibits a strong first oscillation $(\approx 7140 \mathrm{eV})$ followed by a decrease in the amplitudes of the oscillations at higher energies $(>7180 \mathrm{eV})$ due to strong multiple scattering effects, a typical behavior for cyano-bridged organometallic compounds. Two pre-edge peaks are present at about $7108 \mathrm{eV}$ and $7114 \mathrm{eV}$. In both PB-Cotton and PB-Linen samples, Air+Light induces a slight shift of the absorption edge towards lower energies. No drastic change is observed in the height of the pre-edge peaks.

The energy at which the absorption edge occurs, defined by the maximum in intensity of the derivative of the XANES spectrum, depends on the average oxidation state of iron. It is determined in Prussian blue by the ratio between Fe(III) and Fe(II) ions. A shift of the edge towards lower energies indicates that this ratio has changed, with an increase of $\mathrm{Fe}$ (II) ions compared to Fe(III) ions. In other words, it is indicative of a reduction of Fe(III) ions.

XANES derivatives of PB-Cotton and PB-Linen faded in Air and Air+Light are displayed in Figure 3. For both samples, the derivatives are dominated by a Gaussian curve centered on average around $7122 \mathrm{eV}$, with a shoulder at $7120 \mathrm{eV}$. The peak at $7122 \mathrm{eV}$ can be attributed to the nonexcited state of Prussian blue and the peak at $7120 \mathrm{eV}$ to the reduced state of Prussian blue (colorless). For the PBCotton sample faded in light, the peak at $7120 \mathrm{eV}$ becomes majority and is accompanied by a change on the XANES spectrum of the first oscillation after the edge (Figure 2). It indicates that Prussian blue has reduced and that the iron environment has been modified. For the PB-Linen sample faded in light, a shift of the XANES derivative towards lower energies is present but to a minor extent, and is not accompanied by a change in the first oscillation after the edge. Therefore, light induces a significant reduction of Fe(III) in Prussian blue when dyed on cotton, while Prussian blue remains stable when dyed on linen. In other words, Prussian blue exposed to light in air seems to be more sensitive to reduction on cotton than on linen.

\section{Textile aging in faded $P B$ dyed textiles}

The reflectance spectra of undyed cotton and linen samples faded under the same conditions than the PB dyed textiles (Air and Air+Light) are displayed in Figure 4. The undyed linen sample does not show any color change in
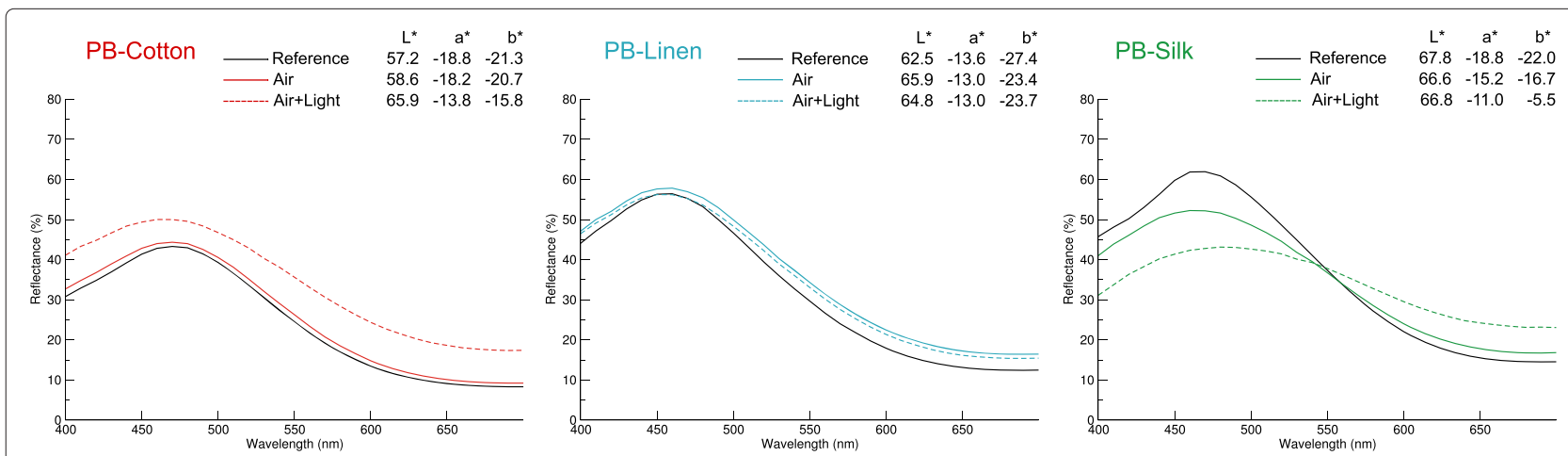

Figure 1 Reflectance spectra and L*a*b* values of PB-dyed textiles before (Reference, black curve) and after Air and Air+Light fading treatments (colored curves). 


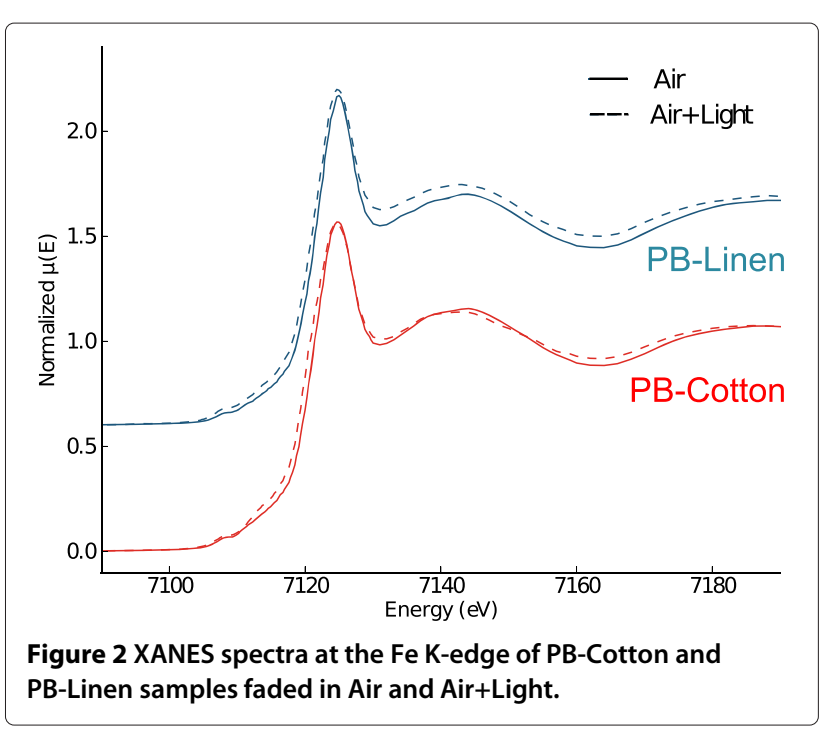

air or when exposed to light. The undyed cotton sample however, exhibits a general increase in $L^{*}$ by 10 units and more reflectance in the blue region of the spectrum. Cotton thus bleaches in air, a phenomenon further enhanced by light. Cellulose bleaching due to exposure to UVA and blue light has been reported in the literature [18]. Therefore, linen is stable when exposed to air and light, while cotton readily ages under these conditions.

Recoloration of faded PB dyed textiles after 3 years of storage The color of PB dyed textiles and undyed textile samples were again analyzed after 3 years storage in the dark and in air. Whatever the type of textile, all PB dyed textiles show the same type of spectra following the 3-year storage period (Figure 5): the reflectance came back to original values in the red region $(600-700 \mathrm{~nm})$ while it decreased in the blue region (400-550nm). Because Prussian blue

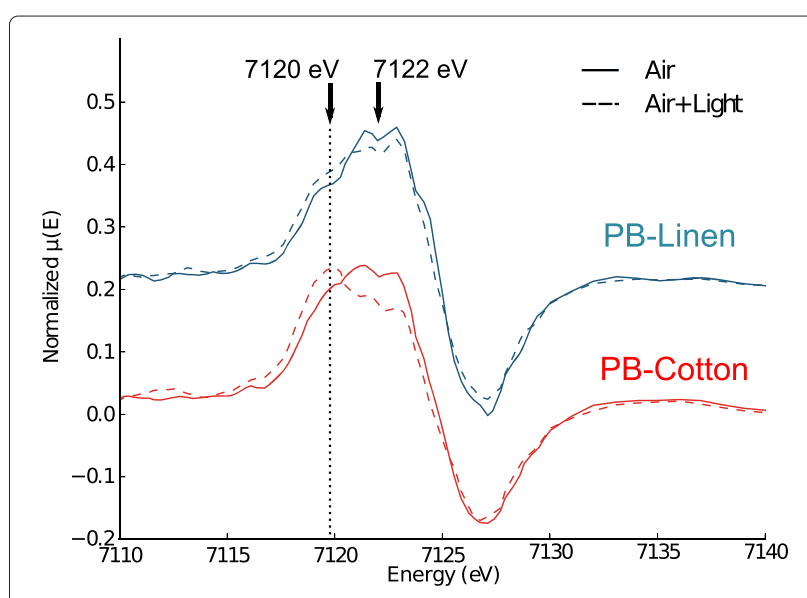

Figure 3 Derivatives of the XANES spectra of PB-Cotton and PB-Linen samples faded in Air and Air+Light. Reduction is visible by a shift of the maximum from $7122 \mathrm{eV}$ to $7120 \mathrm{eV}$.

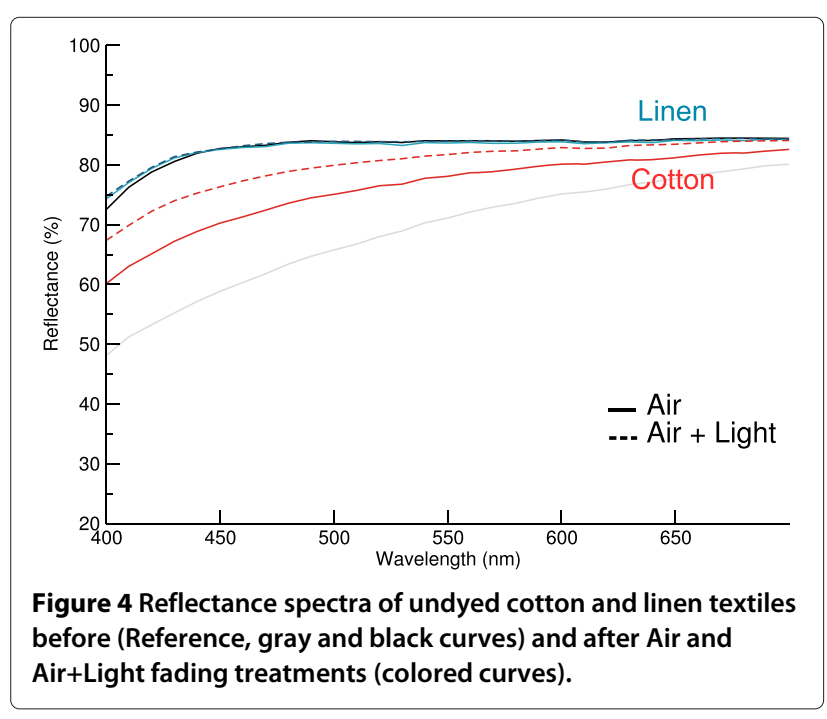

mostly absorbs around $\approx 680 \mathrm{~nm}$, a discoloration of the pigment should be visible in this region. The reflectance spectra thus suggest that Prussian blue mostly recovered its color after 3 years of storage. In contrast, the color of undyed cotton and linen samples is further modified. Linen is yellower than before storage; cotton is still whiter than the reference, but less white than before storage. The yellowing of the cotton on storage, after the immediate light-induced bleaching, illustrates the complex and multiple degradation mechanisms of cellulose [19]. These results indicate an irreversible degradation of the textiles in air.

\section{Prussian blue and textile substrate act as a redox system}

In summary, cotton is a sensitive substrate that readily "ages" in air and light. According to XANES, Prussian blue dyed on cotton is sensitive to light and reduces significantly. On the contrary, linen is a stable substrate and Prussian blue dyed on linen does not readily reduce under light. These findings corroborate those found for PB-paper systems $[6,10]$ and evidence the influence of textile substrate on Prussian blue lightfastness. This can be explained by considering the redox chemistry of Prussian blue. The reduction of Prussian blue implies the migration of electrons and cations into the structure:

$$
\mathrm{KFe}^{\mathrm{III}}\left[\mathrm{Fe}^{\mathrm{II}}(\mathrm{CN})_{6}\right]+\mathrm{K}^{+}+e^{-}<=>\mathrm{K}_{2} \mathrm{Fe}^{\mathrm{II}}\left[\mathrm{Fe}^{\mathrm{II}}(\mathrm{CN})_{6}\right]
$$

Thus, if the substrate is able to supply cations and electrons (by oxidation or generation of radicals), it allows Eq. (1) to occur. Cotton is a natural cation reservoir and generates hydroxyl radicals when exposed to UV and blue light [18]. It thus promotes Prussian blue reduction, which readily fades in such systems. On the contrary, linen is stable in air and light and thus cannot supply the necessary 


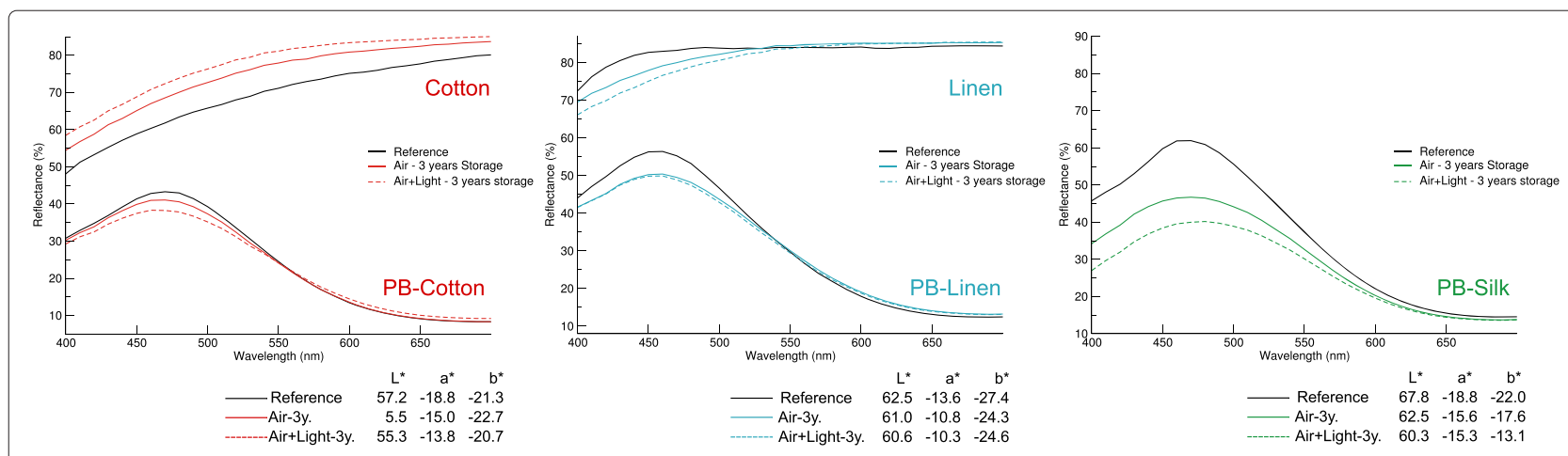

Figure 5 Reflectance spectra of PB dyed textiles and undyed cotton and linen textiles before fading treatment (Reference, black curve) and after fading in Air and Air+Light followed by 3 years of storage (colored curves). $L^{*} a^{*} b^{*}$ values are given for PB dyed textiles.

species for Prussian blue reduction, which remains stable in such systems. It is important to note that this oneto-one relationship was possible to study here because we analyze model samples, where there are no other potential sources of cations and electrons, such as impurities or other dyes. Not studied here is the influence of Prussian blue on the photodegradation process of the textiles. Trace metal ions (such as Fe) enhance the photodegradation process of several fibers, including cotton. For instance, they participate to the oxidative degradation of cellulose $[20,21]$ and increase the concentration of hydroxyl radical generated upon light exposure [18]. As well, iron influences the degradation of cellulose in iron gall-ink manuscripts [22]. Therefore, the participation of Prussian blue to the degradation process of the fibers cannot be ruled out, to the contrary, and would be interesting to investigate. Finally, the type of mordant (here aluminium sulfate) and its role in the redox process would be worth investigating. There are studies attesting the significant effect of mordant on color fastness of dyed textiles (see [3] and references therein), but a detailed physicochemical investigation at the molecular level is missing so far.

\section{Fading of PB dyed textiles in anoxia}

The reflectance spectra of $\mathrm{PB}$ dyed textiles before and after fading treatments in Anoxia and Anoxia+Light are displayed in Figure 6. The global color change associated with anoxia fading follows the same trend whatever the type of textile: Samples in anoxia exhibit an increase in lightness $\left(L^{*}\right)$, accompanied by an increase of $b^{*}$. Compared to the References, $\Delta E^{*}$ values reach 27 for PB-Cotton, 25 for PB-Linen and 31 for PB-Silk faded in Anoxia+Light. The color change is greater than for samples faded in Air+Light.

These findings suggest that the fading mechanism in anoxia involves different factors than the fading in air. In air, the textile was shown to play a major role on the global color change of the sample; in anoxia, color change is relatively independent of the type of textile. Moreover, the global color change in anoxia is larger than in air (compare for instance $\Delta E^{*}$ values of 10 and 27 for PB-cotton faded in Air+Light and Anoxia+Light respectively). This larger color change does not come likely from the textile, because undyed textiles faded in anoxia are stable (Figure 7). It must therefore come from a larger discoloration of Prussian blue in anoxia than in air, a

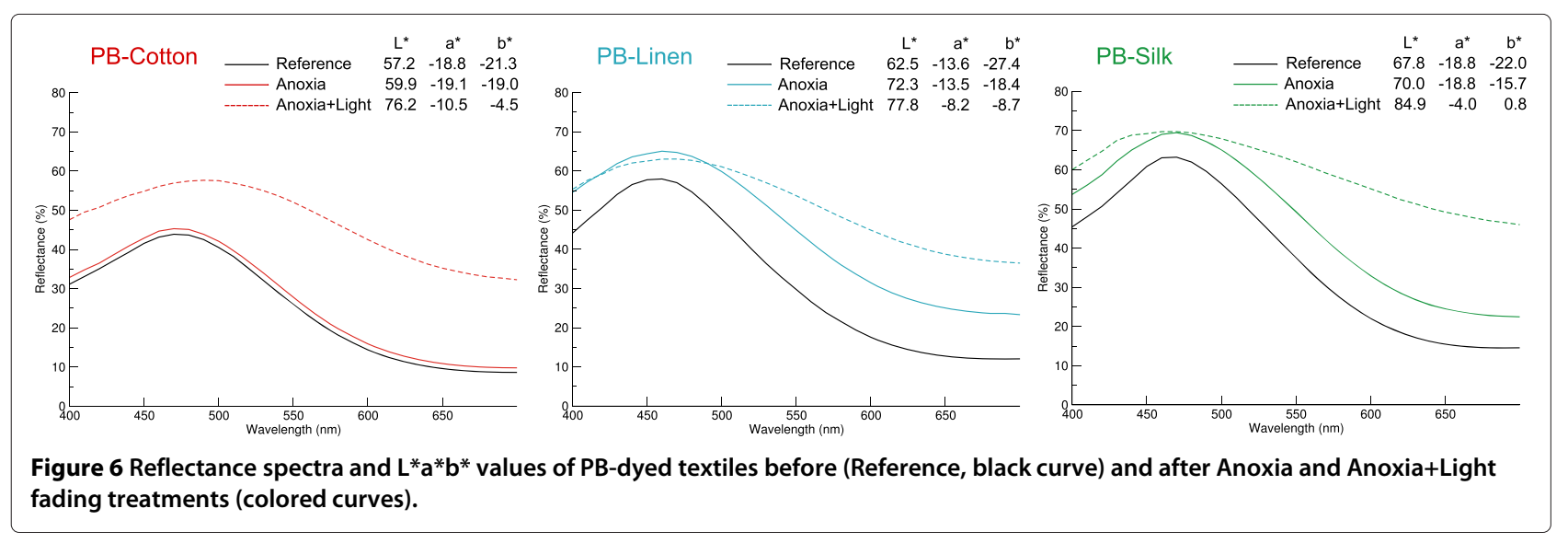




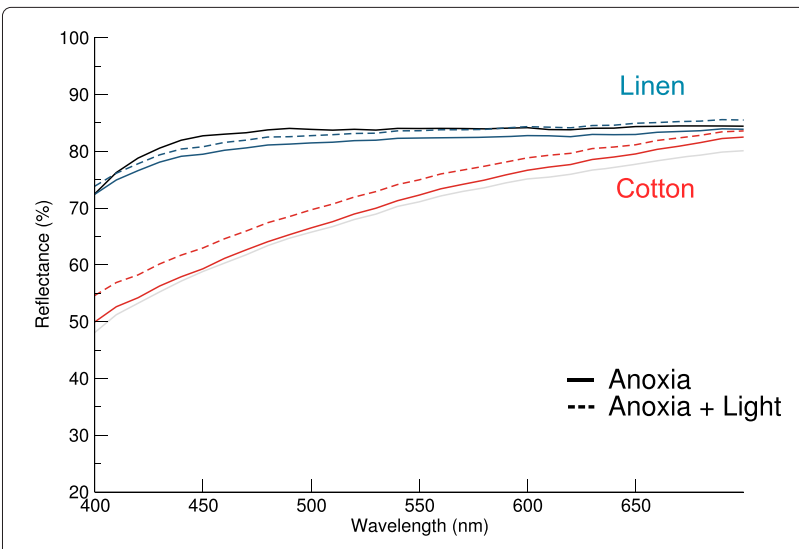

Figure 7 Reflectance spectra of undyed cotton and linen textiles before (Reference, gray and black curves) and after Anoxia and Anoxia+Light fading treatments (colored curves).

finding supported by a recent study which showed by $\mathrm{X}$-ray absorption spectroscopy that Prussian blue in PBpaper model samples reduces more readily and to a larger extent in anoxia than in air [10]. In summary, contrary to air, the large fading of PB dyed textiles in anoxia seem to come mostly from Prussian blue discoloration and not from textile aging.

What remains unclear is whether the global fading mechanism presented in Eq. 1, which involves the migration of cations and electrons from the substrate within the reduced PB structure, is still valid in anoxia. We introduce Figure 8 to highlight and discuss some points concerning this open question. In air, the reduction of Prussian blue is made possible by the oxidation of the textile. Reoxidation of Prussian blue however occurs, limiting the amount of reduced Prussian blue. In anoxia, the substrate is more stable than in air and thus does not support Prussian blue reduction. However, even if the amount of Prussian blue which is reduced is limited by the stability of the substrate, the absence of oxygen prevents PB reoxidation, so that the reduced state remains stable and eventually become predominant. This scenario agrees with results gathered in this paper and previous literature [6,10]. It however does not take into account humidity of the environment, water molecules adsorbed within the substrate, and those present in the Prussian blue structure. Humidity likely influences the fading kinetics of Prussian blue (by promoting migrations in and out of the structure) and could potentially also influence Prussian blue reduction. Indeed, water molecules present within the interstitial sites of the PB cubic lattice are necessary for electronic diffusion to occur in Prussian blue thin films [23], and water transfer can compete with cation transfer in the redox process [24]. Further investigation of the role of humidity and water transfer on global color changes and on Prussian blue reduction could thus help in confirming and refining the scenarios presented in Figure 8.

\section{Implications for conservation of PB artefacts}

These findings bring new insights concerning the choice of suitable environmental conditions to conserve Prussian blue dyed textiles. As shown in this paper, PB dyed textiles in air and exposed to light undergo a mild and reversible discoloration of Prussian blue together with an irreversible degradation of the substrate. Oxygen plays an antagonistic role: it allows reoxidation of the reduced Prussian blue and thus prevent strong Prussian blue discoloration in a dynamic redox process; but it also induces the degradation of the cotton substrate, which irreversibly ages as evidenced by the study of undyed cotton and by the samples after 3 years of storage in the dark. Therefore, choice of long-term display, permanent storage or repeated displays of $\mathrm{PB}$ artefacts in air alternated with storage in the dark to let $\mathrm{PB}$ recolor, should be principally motivated on the basis of the type of textile and the state of degradation of the textile. Concerning Prussian blue itself, structural changes after recoloration were not investigated so that no conclusion can be stated on the impact of discolorationrecoloration cycles on its long-term conservation.

In anoxia, the substrate is protected from oxidative degradation processes and its participation to the fading of Prussian blue is thus minimized. However, the absence of oxygen prevents reoxidation of Prussian blue that ultimately undergoes a larger discoloration than in air. This discoloration should be reversible upon re-exposure to air, although further study is required to ultimately quantify
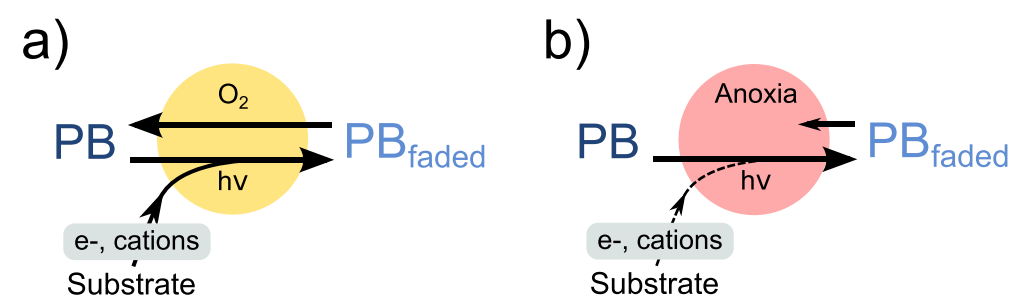

Figure 8 Schematic view of the light fading mechanism of Prussian blue dyed textiles in air (a) and in anoxia (b). Right arrow: Prussian blue reduction influenced by light and substrate; Left arrow: Prussian blue reoxidation influence by oxygen content of the environment. 
the level of pigment recovery, both from a color perspective and from a structural point of view. Indeed, the mechanism behind anoxia fading of PB dyed textiles is still largely unknown. We have proposed here a possible scenario to explain the different behaviors of PB dyed textiles in air and in anoxia. Considering the presence state of knowledge, anoxia can be safely used for strongly sensitive PB-dyed textiles, i.e. objects in which the textile substrate is sensitive and likely to degrade and compromise the stability or integrity of the object.

\section{Conclusions}

The mechanisms of light fading in air and anoxia of PB dyed textiles were investigated by a combination of spectrophotometry and XANES measurements at the Fe K-edge. This procedure proved to be successful in monitoring the global color changes in faded PB dyed textiles and getting some physico-chemical understanding of the source of the discoloration (whether substrate or pigment). From the analysis of a series of samples consisting of PB dyed on cotton, linen and silk, that underwent light and anoxia fading treatments, we concluded the following:

- Light fading of PB dyed textiles implies a reduction of Prussian blue.

- In air, Prussian blue discoloration depends mainly on the sensitivity of the substrate: the more sensitive is the substrate to light and air, the more Prussian blue fades via a redox process that involves both pigment and substrate.

- In anoxia, Prussian blue is "sensitized" and discolors strongly when light is applied. The substrate is protected from oxidative degradation processes and thus plays a minor role in PB fading.

A basic mechanism focusing on the interplay Prussian blue-textile-environment, was proposed to explain the different fading behaviors of $\mathrm{PB}$ dyed textiles in air and anoxia. Further studies focusing on the influence of humidity, the role of the mordant, or the impact of Prussian blue on textile degradation could help in refining this scenario and get a more comprehensive picture of the complex physico-chemistry happening in Prussian blue dyed textiles, and in Prussian blue artefacts in general.

\section{Endnote}

${ }^{\mathrm{a}} \mathrm{Here}$, we use the term anoxia to describe an environment with less than $0.1 \%$ oxygen, in coherence with previous works $[3,4]$.

\section{Additional file}

Additional file 1: Reflectance spectra of the second series of Prussian blue dyed textiles faded under light and anoxia.

\section{Competing interests}

The authors declare that they have no competing interests.

\section{Authors' contributions}

CG and MAL conceived the study; all authors participated to sample preparation, measurements and result analysis; CG wrote the manuscript. All authors read and approved the final manuscript.

\section{Acknowledgements}

We thank Sebastien Pelletier for having dyed the textiles, and acknowledge SOLEIL for access to synchrotron radiation facilities. Financial support by the Transnational Access to Research Infrastructures activity in the 7th Framework Programme of the EU (CHARISMA Grant Agreement n. 228330) is acknowledged. Claire Gervais thanks the Swiss National Foundation for support through the SNSF professorship grant n. 138986.

\section{Author details}

${ }^{1}$ Bern University of the Arts, Fellerstrasse 11, 3027 Bern, Switzerland. 2 IPANEMA, USR 3461 CNRS/MCC, at Synchrotron SOLEIL, BP48 Saint-Aubin, 91192 Gif-sur-Yvette, France. ${ }^{3}$ Centre de Recherche sur la Conservation, USR 3224, CNRS/MCC/MNHN, 36 rue Geoffroy Saint Hilaire, 75005 Paris, France. ${ }^{4}$ Synchrotron SOLEIL, BP48 Saint-Aubin, 91192 Gif-sur-Yvette, France.

Received: 16 May 2014 Accepted: 31 October 2014

Published online: 26 November 2014

References

1. Berrie BH: Prussian blue. In Artist's Pigments: A Handbook of Their History and Characteristics Volume 3, Chap. 7. Edited by Feller RL, FitzHugh EW. Washington D.C.: National Gallery of Art; 1997:191-217.

2. Kirby J, Saunders D: Fading and colour change of Prussian blue: methods of manufacture and the influence of extenders. Nat/ Gallery Tech Bull 2004, 25:73-99.

3. Rowe S: The effect of insect fumigation by anoxia on textiles dyed with Prussian blue. Stud Conservation 2004, 49:259-270.

4. Korenberg C: The photo-ageing behaviour of selected watercolour paints under anoxic conditions. British Museum: Tech Res Bull 2008, 2:49-57.

5. Padfield T, Landi S: The light fastness of the natural dyes. Stud Conservation 1966, 11:181-196.

6. Gervais C, Languille M-A, Reguer S, Gillet M, Pelletier S, Garnier C, Vicenzi $E P$, Bertrand $L$ : Why does Prussian blue fade? Understanding the role(s) of the substrate. J Anal Atomic Spectrom 2013, 28(10):1600.

7. del Hoyo-Meléndez JM, Mecklenburg MF: The use of micro-fading spectrometry to evaluate the light fastness of materials in oxygen-free environments. Spectrosc Lett 2011, 44:113-121.

8. Ware M: Cyanotype: The History, Science, and Art of Photographic Printing in Prussian Blue. Bradford, UK: National Museum of, Photography, Film, and Television; 1999.

9. Nassau K: The Physics and Chemistry of Color: The Fifteen Causes of Color, Vol 1: John Wiley and Sons; 1983. 147-148.

10. Gervais C, Languille M-A, Reguer S, Gillet M, Vicenzi EP, Chagnot S, Baudelet $F$, Bertrand $L$ : "Live" Prussian blue fading by time-resolved X-ray absorption spectroscopy. Appl Phys A 2013, 111(1):15-22.

11. Samain L, Gilbert B, Grandjean F, Long GJ, Strivay D: Redox reactions in Prussian blue containing paint layers as a result of light exposure. J Anal Atomic Spectrom 2013, 28:524.

12. Lerwill A, Townsend JH, Thomas J, Hackney S, Caspers C, Liang H: Photochemical colour change for traditional watercolour pigments in low oxygen levels. Stud Conservation.

13. Lavédrine B, Pesme CC, Garnier C, Gillet M: Etude des possibilités d'exposition permanente de documents réputés fragiles: le cas des héliographies de Louis Ducos du Hauron. Tracé/Support 2005, 5:38-44.

14. Chevreul ME: Ueber die Einwirkung des Lichtes auf das Berliner Blau im luftleeren Raume. Adv Synth Catalysis 1837:187-190.

15. Napier J: A Manual of Dyeing and Dyeing Receipts, Comprising a System of Elementary Chemistry, as Applied to Dying, with Receipts for the General Reader for Dyeing on Cotton, Silk and Wool, with Coloured Pattern of Cloth of Each Fabric. 3rd edn. London, UK: Charles, Griffin and Co; 1875.

16. Newville M: IFEFFIT: interactive XAFS analysis and FEFF fitting. J Synchrotron Radiat 2001, 8:322-324. 
17. Ware M: Prussian blue: artists' pigment and chemists' sponge. J Chem Educ 2008, 85(5):612-620.

18. Millington KR, Kirschenbaum LJ: Detection of hydroxyl radicals in photoirradiated wool, cotton, nylon and polyester fabrics using a fluorescent probe. Coloration Technol 2002, 118:6-14.

19. Strlič M, Kolar J: Ageing and Stabilisation of Paper. Ljubljana, Slovenia: National and University Library; 2005.

20. Millington KR: Photoyellowing of wool. Part 1: factors affecting photoyellowing and experimental techniques. Coloration Technol 2006, 122:169-186.

21. Šelih VS, Strlič M, Kolar J, Pihlar B: The role of transition metals in oxidative degradation of cellulose. Polymer Degradation Stability 2007, 92(8):1476-1481.

22. Rouchon V, Duranton M, Burgaud C, Pellizzi E, Lavedrine B, Janssens $K$, de Nolf W, Nuyts G, Vanmeert F, Hellemans K: Room-temperature study of iron gall ink impregnated paper degradation under various oxygen and humidity conditions: Time-dependent monitoring by viscosity and $X$-ray absorption near-edge spectrometry measurements. Anal Chem 2011, 83(7):2589-2597.

23. Feldman B, Murray R: Electron diffusion in wet and dry Prussian blue films on interdigitated array electrodes. Inorg Chem 1987, 8:1702-1708.

24. Kim K, Jureviciute I, Bruckenstein S: Electrochemical quartz crystal microbalance studies of anion and ph effects on water fluxes accompanying redox switching of prussian blue. Electrochimica Acta 2001, 46(26-27):4133-4140.

doi:10.1186/s40494-014-0026-

Cite this article as: Gervais et al.: Light and anoxia fading of Prussian blue dyed textiles. Heritage Science 2014 2:26.

\footnotetext{
Publish with ChemistryCentral and every scientist can read your work free of charge

"Open access provides opportunities to our colleagues in other parts of the globe, by allowing anyone to view the content free of charge."

W. Jeffery Hurst, The Hershey Company.

- available free of charge to the entire scientific community

- peer reviewed and published immediately upon acceptance

- cited in PubMed and archived on PubMed Central

- yours - you keep the copyright

Submit your manuscript here: 